\title{
Factors associated with Obesity among Korean Adolescents based on the Seventh Korea National Health and Nutrition Examination Survey (2016)
}

\author{
Hyun Young Koo ${ }^{1}$, Eun Kyung Lee ${ }^{2}$ \\ ${ }^{1}$ Professor, College of Nursing, Daegu Catholic University, Research Institute of Nursing Science, Daegu; ${ }^{2}$ Assistant Professor, College of Nursing, Daegu Catholic \\ University, Research Institute of Nursing Science, Daegu, Korea
}

Purpose: This study was conducted to examine factors associated with obesity among Korean adolescents. Methods: The participants were 436 Korean adolescents aged 12 18 years who took part in the seventh Korea National Health and Nutrition Examination Survey (2016). The data were analyzed by descriptive statistics, the $x^{2}$ test, one-way analysis of variance, and multinomial logistic regression using complex sample analysis. Results: Among the participants, 9.7\% were classified as being obese, and $11.9 \%$ as being overweight. Several health parameters, including systolic blood pressure, diastolic blood pressure, waist circumference, and triglyceride, fasting blood sugar, and alanine aminotransferase levels, varied according to obesity. Distorted perceptions of body shape showed a significant negative association with overweight, and carbohydrate intake was negatively associated with obesity. Conclusion: These findings indicate that obesity in Korean adolescents was associated with lifestyle and health parameters. Therefore, intervention programs for obese or overweight adolescents should focus on preventing them from developing health problems.

Key words: Adolescents; Obesity; Overweight; Life style

\author{
Corresponding author Eun Kyung Lee \\ https://orcid.org/0000-0003-4299-1415 \\ College of Nursing, Daegu Catholic University, \\ 33 Duryugongwon-ro, 17 gil, Nam-gu, Daegu 42472, Korea \\ TEL +82-53-650-4976 FAX +82-53-650-4392 \\ E-MAIL leeek@cu.ac.kr
}

Received Sep 6, 2018 Revised Oct 10, 2018 Accepted Oct 26, 2018 (a) This is an Open Access article distributed under the terms of the Creative Commons Attribution NonCommercial License (http://creativecommons.org/licenses/by-nc/4.0/) which permits unrestricted noncommercial use, distribution, and reproduction in any medium, provided the original work is properly cited.

\section{INTRODUCTION}

The prevalence of obesity in Korea has gradually increased from $1.4 \%$ of adolescents in 1981 [1] to $11.7 \%$ of elementary, middle, and high school students in 2010, and further to $12.9 \%$ in 2014 [2]. As adolescence is a time when major psychological changes take place, in addition to physical growth, obesity has a great influence on school adaptation or academic achievement, as well as on physical health [3]. Furthermore, adolescents sometimes think they are more overweight or obese than their actual physical state due to an excessive obsession with their body and appearance [4]. Therefore, adolescents should be encouraged to achieve physical growth and psychological developmental tasks through the prevention and management of adolescent obesity in order to help them become healthy adults.

Obesity is a state of excessive fat accumulation. As directly measuring body fat to diagnose obesity is complex and costly, obesity is generally categorized using body mass index (BMI), a value calculated by dividing body weight measured in kilograms by the square of height measured in meters $\left(\mathrm{kg} / \mathrm{m}^{2}\right)$. Adults in the Asia-Pacific Region are considered to be obese when their BMI is $25 \mathrm{~kg} / \mathrm{m}^{2}$ or more, overweight when their BMI is $23 \mathrm{~kg} / \mathrm{m}^{2}$ or more and less than $25 \mathrm{~kg} / \mathrm{m}^{2}$, and normal when their BMI is $18.5 \mathrm{~kg} / \mathrm{m}^{2}$ or more and less than $23 \mathrm{~kg} / \mathrm{m}^{2}$ 
[5]. In particular, since the height and weight of children and adolescents continuously change during their growth and development, BMI percentiles according to age and sex are used to diagnose obesity for children and adolescents aged between 2 years and 20 years. They are classified as obese at greater than or equal to the 95th percentile, overweight at greater than or equal to the 85th percentile and less than the 95th percentile, and normal at greater than or equal to 5 th percentile and less than the 85th percentile [6].

Obesity occurs due to genetic and environmental factors, although genetic or endocrine disorders are implicated in rare cases, and it is known that sociodemographic characteristics, such as sex, age, and socioeconomic status, and lifestyle factors, such as nutrient intake, activity levels, and sleep, show complex associations with obesity [6,7]. A recent study conducted on Korean adolescents reported that the risk of obesity was higher in male adolescents than in female adolescents $[8,9]$, as adolescents became older [8], and in adolescents with a lower family income $[8,9]$.

The environmental factors of obesity, dietary habits, and physical activity are the greatest contributors to obesity [10], and obesity is associated with unhealthy dietary habits such as skipping meals, binge eating, fast food consumption, and a high intake of fat [11]. Korean obese adolescents consume an excessive amount of nutrients such as fat, cholesterol, and sodium, and experience difficulties in limiting their intake of high-calorie junk foods [12]. Obesity occurs as fat accumulates on the body when energy consumption is smaller than physical activity. Therefore, the risk of obesity is high when a person engages in small amounts of physical activity and sits for long hours [13]. In previous studies, the risk of obesity in adolescents became higher as adolescents spent longer times sitting and playing games [9]. Furthermore, insufficient sleep decreases insulin sensitivity and increases glucose tolerance, which hampers glucose metabolism, reduces levels of leptin (a hormone that causes satiety), and increases levels of ghrelin (an appetite-stimulating hormone) [14]. Hence, it has been reported that less sleep increases the risk of adolescents' becoming obese [9].

Obesity is accompanied by various health problems that are generally considered to be adult diseases, such as type 2 diabetes, dyslipidemia, obstructive sleep apnea, nonalcoholic fatty liver disease, and hypertension $[15,16]$. In particular, insulin resistance, with concomitant reductions in insulin function, can cause metabolic syndrome, which increases the risk of hypertension, dyslipidemia, and hyperglycemia; these conditions are in turn linked to cardiovascular disease [5]. Experts have encouraged overweight adolescents with a BMI at or above the 85th percentile and below the 95th percentile to undergo testing for blood lipid levels and fasting blood sugar, hemoglobin A1c (HbA1c), and liver enzyme levels if blood lipid levels are elevated or if adolescents have a family history of hypertension, smoking, and obesity. Obese adolescents with a BMI at or above the 95th percentile are encouraged to undergo testing for blood lipid, fasting blood sugar, HbA1c, and liver enzyme levels even if they have no risk factors because the health problems that accompany obesity in adolescents continue into adulthood [6].

Measures such as stress control, dietary improvements, and increases in physical activity have been suggested to manage obesity in adolescents [17], but the effects of these interventions remain controversial. Furthermore, although studies have investigated the consequences of obesity in adolescents, there are limitations in generalizing and quantifying the results of these studies due to the use of convenience sampling in limited geographical regions or self-reported data. Therefore, these issues should be approached by using data extracted through systematic sampling across the nation instead of convenience sampling, dividing participants according to obesity and overweight defined by BMI percentiles according to age and sex, and analyzing directly-measured physical parameters and the results of clinical laboratory tests, as well as self-reported information.

As such, this study aimed to investigate whether obesity among Korean adolescents was associated with sociodemographic characteristics, lifestyle factors, and health parameters using raw data from the first year of the seventh Korea National Health and Nutrition Examination Survey (KNHANES, 2016) and to analyze the factors that influenced obesity in adolescents, with the goal of using these results as a basis for establishing intervention strategies to prevent and manage obesity in adolescents.

The purpose of this study was to examine the associations of obesity among Korean adolescents with sociodemographic characteristics, lifestyle factors, and health parameters, and to analyze the factors that influenced obesity in adolescents using the raw data of the first year of the seventh KNHANES. The specific purposes are summarized as follows.

- To investigate the associations of obesity among Korean adolescents with sociodemographic characteristics, lifestyle factors, and health parameters

- To analyze the factors that influenced obesity in adolescents

\section{METHODS}

\section{Design}

This study utilized a descriptive survey design to investigate the associations of obesity among Korean adolescents 
with sociodemographic characteristics, lifestyle factors, and health parameters, and to analyze the factors that influenced obesity in adolescents using the raw data from the first year of the seventh KNHANES.

\section{Subjects}

This study analyzed the raw data from the first year of the seventh KNHANES (2016). The KNHANES is a regularlyconducted survey that investigates levels of health, health behavior, and food and nutrient intake throughout the nation based on Article 16 of the National Health Promotion Act, which was enacted in 1995. For the first year of the seventh KNHANES, the nation was divided into 192 survey districts, and 23 sample households per district were selected using systematic sampling. The survey was then conducted among household members aged 1 year or older as subjects [18]. In the first year of the seventh KNHANES, 8,150 people from 3,513 households participated. The present study included 436 participants aged between 12 and 18 years whose height and weight were measured. Underweight participants were excluded.

\section{Instruments}

\section{1) Obesity}

Obesity was classified using measurements of height and weight. BMI $\left(\mathrm{kg} / \mathrm{m}^{2}\right)$ was calculated using height in meters measured by an anthropometer (Seca 225, Seca, Germany) and weight in kilograms measured using a scale (GL-6000-20, G-tech, Korea), and the subjects were classified as obese if they were at or above the 95th BMI percentile according to age and sex, as overweight if they were at or above the 85th percentile and below the 95th percentile, and as being of normal weight if they were at or above the 5th percentile and below the 85th percentile [5,19].

\section{2) Sociodemographic characteristics}

Sociodemographic characteristics were investigated in terms of age, sex, place of residence, household income, and self-rated body shape, based on a previous study that reported that sex $[8,9]$, age [8], socioeconomic status [8,9], and self-perceptions of obesity [4] were associated with obesity. As for place of residence, those who lived in a neighborhoodlevel administrative unit (dong) were classified as living in an urban area, while the administrative units of towns (eup) and townships (myeon) were considered rural areas. Household income was classified as high ( $>3$ million KRW), middle-high ( $>2$ million KRW, $\leq 3$ million KRW), middle-low ( $>1$ million $\mathrm{KRW}, \leq 2$ million KRW), or low ( $\leq 1$ million KRW). Self-rated body shape was classified as very slim, slightly slim, average, slightly fat, and very fat. Distorted perceptions of body shape were investigated by discrepancies between self-rated body shape and the BMI-based categorization. More specifically, cases in which subjects with a normal weight perceived themselves as average, overweight subjects perceived themselves as slightly fat, and obese subjects perceived themselves as very fat were considered to indicate no distortion, while all other cases were considered to indicate a distorted perception of body shape.

\section{3) Lifestyle factors}

Based on a previous study showing that obesity was associated with nutrient intake [8,12], physical activity [6,9], and sleep $[9,14,20]$, lifestyle factors were investigated using data on nutrient intake, physical activity, sleep, and efforts to control weight. Nutrient intake was analyzed in terms of calorie, protein, fat, and carbohydrate intake calculated through an analysis of the foods eaten on the day before the investigation using the 24-hour recall method. Physical activity was analyzed based on self-reported daily high-intensity exercise or leisure activity time, moderate-intensity exercise or leisure activity time, and sitting or lying time. The average reported daily sleeping time on weekdays and weekends was used to analyze sleep. Lastly, efforts to control weight were classified as efforts to reduce weight, efforts to maintain weight, efforts to gain weight, and no efforts to control weight over the previous year.

\section{4) Health parameters}

Based on the results of previous research [6,21], the following health parameters were analyzed: systolic blood pressure, diastolic blood pressure, waist circumference, total cholesterol and triglyceride levels (blood lipid levels), fasting blood sugar and $\mathrm{HbA1c}$ levels, and aspartate aminotransferase (AST) and alanine aminotransferase (ALT) levels (liver enzyme levels). For blood pressure, a nurse certified by the Korean Society of Hypertension took 3 measurements, and the average of the second and third measurements was used. The nurse had the subject rest in a seated position for about 5 minutes, and then measured the subject's blood pressure using a mercury sphygmomanometer (Baum 0850, W.A. Baum, USA). For waist circumference, a nurse or a health-related major wrapped a measuring tape (Seca 200, Seca, German) around the midpoint between the lower part of the last rib and the upper part of iliac crest on the same side of the subject and measured the value when the subject breathed out. Blood lipid, fasting blood sugar, $\mathrm{HbA1c}$, and liver enzyme levels were analyzed through clinical chemical test results using blood samples extracted from subjects who were instructed to fast after dinner on the day before the test. 


\section{Data Collection}

Approval (CUIRB-2018-0010) was obtained from the Institutional Review Board (IRB) of D university, and then the raw data from the first year of the seventh KNHANES was downloaded after entering the appropriate user information on the homepage of the KNHANES of the Korea Centers for Disease Control and Prevention. The first year of the seventh KNHANES was conducted without IRB approval, since it belonged to the category of research conducted by the nation for the purpose of public welfare according to Article 2, Subparagraph 1 of the Bioethics and Safety Act and Article 2, Paragraph 2, Subparagraph 1 of the Enforcement Regulation of the Act. The first year of the seventh KNHANES was conducted between January and December 2016 by the Ministry of Health and Welfare and the Korea Centers for Disease Control and Prevention. The health survey and check-up investigations were conducted in mobile check-up vehicles through interviews, and direct measurements and nutrition surveys were conducted through interviews administered by a nutrition researcher who visited the subjects' household 1 week later. The Korea Centers for Disease Control and Prevention provided only de-identified data to prevent the estimation of personal information, in compliance with the Personal Information Protection Act and the Statistics Act.

\section{Data Analysis}

As the KNHANES is recommended to be extracted using 2-phase stratified cluster sampling and analyzed in a way that reflects the complex sample design [18], weights, stratification variables, and clustering variables, which are complex sample design factors, were designated and analyzed using SPSS version 25.0 (IBM Corp., Armonk, NY, USA).

Obesity status in adolescents was presented using descriptive statistics, and the associations of obesity with sociodemographic characteristics, lifestyle factors, and health parameters were analyzed using the Rao-Scott $x^{2}$ test and one-way analysis of variance considering the complex sample design. To identify associations of obesity status in adolescents with sociodemographic characteristics and lifestyle factor-related variables, multinomial logistic regression analysis was used, and the results are presented as odds ratios (ORs) and 95\% confidence intervals (CIs).

\section{RESULTS}

\section{Obesity Status of Adolescents}

Of the adolescent subjects, $68.9 \%(n=336)$ were found to be of normal weight, $9.5 \%(\mathrm{n}=37)$ to be underweight, $11.9 \%(\mathrm{n}=$ 54) to be overweight, and $9.7 \%(n=46)$ to be obese. A total of 436 adolescents were analyzed after excluding underweight subjects as part of the study design.

\section{Differences in Obesity in Adolescents according to Sociodemographic Characteristics}

There were no significant differences in age, sex, place of residence, and household income among the normal-weight, overweight and obese groups, but self-rated body shape and distorted perceptions of body shape showed significant differences (Table 1).

In terms of self-rated body shape, $5.1 \%, 24.9 \%, 53.8 \%$, $15.9 \%$, and $0.3 \%$ of the normal-weight group perceived themselves to be very slim, slightly slim, average, slightly fat, and very fat, respectively. In contrast, $2.4 \%, 88.1 \%$, and $9.5 \%$ of the overweight group perceived themselves to be average, slightly fat, and very fat, respectively, and $1.3 \%, 56.4 \%$, and $42.3 \%$ of the obese group perceived themselves to be average, slightly fat and very fat, respectively $\left(x^{2}=39.50, p<.001\right)$. Distorted perceptions of body shape were found in $46.2 \%$ of the normal-weight group, $11.9 \%$ of the overweight group, and $57.7 \%$ of the obese group $\left(x^{2}=13.33, p<.001\right)$.

\section{Difference in Obesity in Adolescents according to Lifestyle Factors}

No significant differences among the groups were found in the daily energy intake of proteins, fats, and carbohydrates; daily high-intensity exercise or leisure activity time, moderate-intensity or leisure activity time, and sitting or lying time; or sleeping hours on weekdays and weekends. However, efforts to control weight showed significant differences (Table 2).

In the normal-weight group, $28.3 \%, 23.4 \%$, and $10.6 \%$ of participants made efforts to lose, maintain, and gain weight, respectively. In the overweight group, $71.2 \%$ and $17.5 \%$ of the participants made efforts to lose and maintain weight, respectively, as did $45.4 \%$ and $28.6 \%$ of the obese group, respectively $\left(x^{2}=99.63, p<.001\right)$.

\section{Differences in Obesity in Adolescents according to Health Parameters}

No significant differences were found in total cholesterol, $\mathrm{HbA1c}$, and AST among the normal-weight, overweight and obese groups, but systolic blood pressure, diastolic blood pressure, waist circumference, and triglyceride, fasting blood sugar, and ALT levels showed significant differences (Table 3).

The average systolic blood pressure in the normal-weight 
Table 1. Obesity in Adolescents according to Demographic Characteristics

$(N=436)$

\begin{tabular}{|c|c|c|c|c|c|c|c|}
\hline \multirow{2}{*}{ Characteristics } & \multirow{2}{*}{ Categories } & $\begin{array}{l}\text { Normal } \\
(\mathrm{n}=336)\end{array}$ & $\begin{array}{c}\text { Overweight } \\
(\mathrm{n}=54)\end{array}$ & $\begin{array}{l}\text { Obesity } \\
(\mathrm{n}=46)\end{array}$ & $\begin{array}{c}\text { Total } \\
(N=436)\end{array}$ & \multirow{2}{*}{$\begin{array}{c}\text { F or } \\
\text { Rao-Scott } x^{2}\end{array}$} & \multirow{2}{*}{$p$} \\
\hline & & $\begin{array}{c}\mathrm{n}(\%)^{*} \text { or } \\
\mathrm{M} \pm \mathrm{SD}\end{array}$ & $\begin{array}{c}\mathrm{n}(\%)^{*} \text { or } \\
\mathrm{M} \pm \mathrm{SD}\end{array}$ & $\begin{array}{c}\mathrm{n}(\%)^{*} \text { or } \\
\mathrm{M} \pm \mathrm{SD}\end{array}$ & $\begin{array}{l}\mathrm{n}(\%)^{*} \text { or } \\
\mathrm{M} \pm \mathrm{SD}\end{array}$ & & \\
\hline Age (year) & & $15.19 \pm 0.11$ & $15.15 \pm 0.27$ & $15.11 \pm 0.31$ & $15.17 \pm 0.09$ & 0.03 & .966 \\
\hline Sex & $\begin{array}{l}\text { Male } \\
\text { Female }\end{array}$ & $\begin{array}{l}168(50.7) \\
168(49.3)\end{array}$ & $\begin{array}{l}35(62.1) \\
19(37.9)\end{array}$ & $\begin{array}{l}24(52.4) \\
22(47.6)\end{array}$ & $\begin{array}{l}227(52.4) \\
209(47.6)\end{array}$ & 1.03 & .358 \\
\hline Place of residence & $\begin{array}{l}\text { Urban } \\
\text { Rural }\end{array}$ & $\begin{array}{r}292(89.2) \\
44(10.8)\end{array}$ & $\begin{array}{r}47(87.5) \\
7(12.5)\end{array}$ & $\begin{array}{r}37(82.7) \\
9(17.3)\end{array}$ & $\begin{array}{r}376(88.2) \\
60(11.8)\end{array}$ & 0.89 & .411 \\
\hline Household income & $\begin{array}{l}\text { Low } \\
\text { Middle-low } \\
\text { Middle-high } \\
\text { High }\end{array}$ & $\begin{array}{r}32(11.9) \\
79(23.7) \\
110(33.0) \\
115(31.4)\end{array}$ & $\begin{array}{r}4(11.8) \\
11(21.4) \\
21(39.6) \\
18(27.2)\end{array}$ & $\begin{array}{r}9(19.6) \\
15(34.1) \\
9(19.4) \\
13(26.9)\end{array}$ & $\begin{array}{r}45(12.7) \\
105(24.5) \\
140(32.4) \\
146(30.4)\end{array}$ & 1.02 & .408 \\
\hline $\begin{array}{l}\text { Self-rated body } \\
\text { shape }^{\dagger}\end{array}$ & $\begin{array}{l}\text { Very slim } \\
\text { Slightly slim } \\
\text { Average } \\
\text { Slightly fat } \\
\text { Very fat }\end{array}$ & $\begin{array}{c}16(5.1) \\
89(24.9) \\
177(53.8) \\
51(15.9) \\
1(0.3)\end{array}$ & $\begin{array}{c}0(0.0) \\
0(0.0) \\
2(2.4) \\
43(88.1) \\
7(9.5)\end{array}$ & $\begin{array}{c}0(0.0) \\
0(0.0) \\
1(1.3) \\
24(56.4) \\
21(42.3)\end{array}$ & $\begin{array}{c}16(3.9) \\
89(19.0) \\
180(41.5) \\
118(29.5) \\
29(6.1)\end{array}$ & 39.50 & $<.001$ \\
\hline $\begin{array}{l}\text { Distorted perception } \\
\text { of body shape }\end{array}$ & $\begin{array}{l}\text { No } \\
\text { Yes }\end{array}$ & $\begin{array}{l}177(53.8) \\
157(46.2)\end{array}$ & $\begin{array}{r}43(88.1) \\
9(11.9)\end{array}$ & $\begin{array}{l}21(42.3) \\
25(57.7)\end{array}$ & $\begin{array}{l}241(57.0) \\
191(43.0)\end{array}$ & 13.33 & $<.001$ \\
\hline
\end{tabular}

${ }^{*}$ Weighted $\% ;{ }^{\dagger}$ Missing data were not included in the values.

Table 2. Obesity in Adolescents according to Lifestyle Factors

$(N=436)$

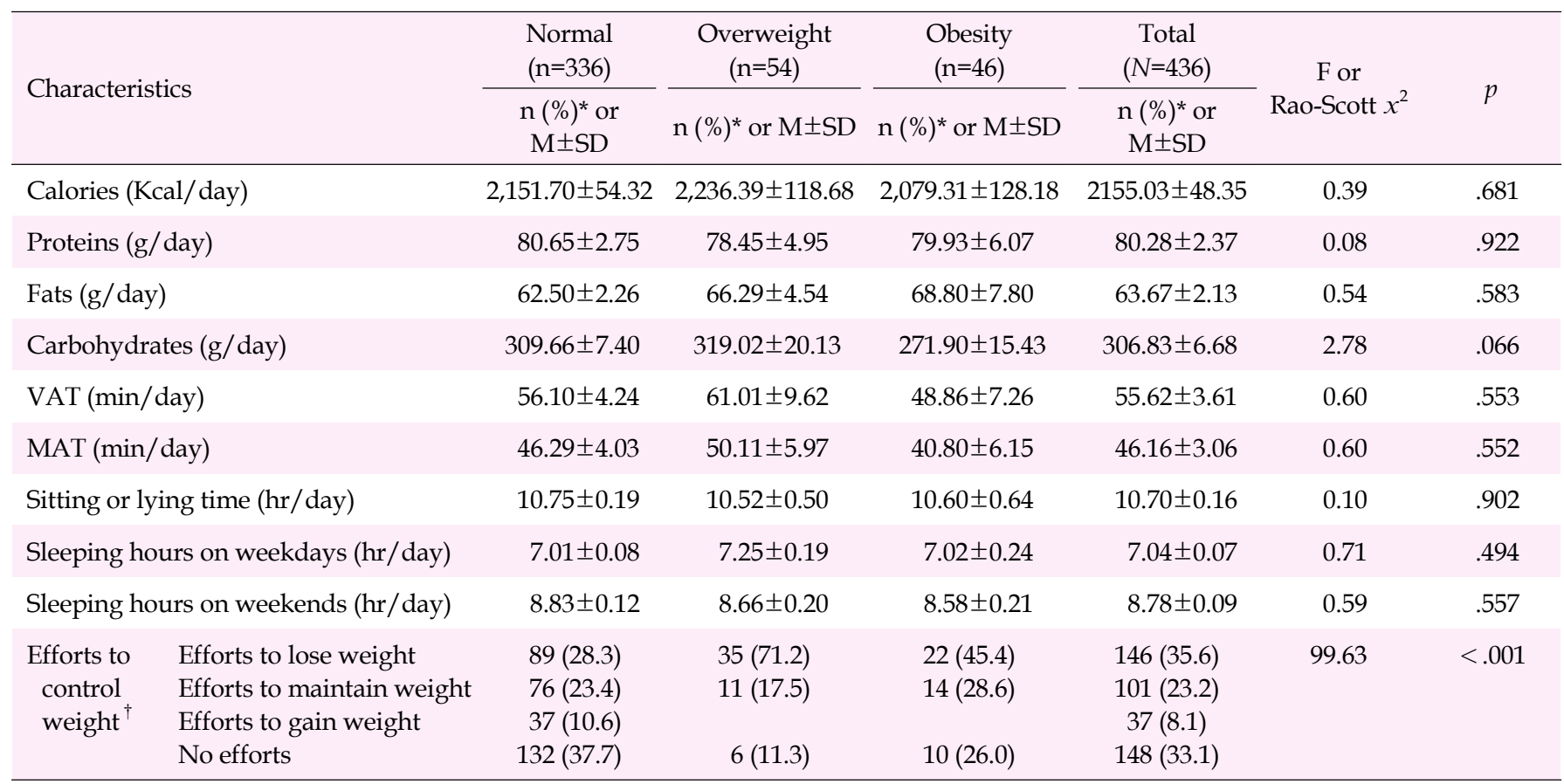

*Weighted $\% ;{ }^{\dagger}$ Missing data were not included in the values; VAT=Vigorous activity time; MAT=Moderate activity time.

group was $108.14 \mathrm{mmHg}$, in contrast to $113.19 \mathrm{mmHg}$ and $120.40 \mathrm{mmHg}$ in the overweight and obese groups, respectively, which was a significant difference ( $\mathrm{F}=24.15, p<.001)$. Diastolic blood pressure also showed a significant difference among the groups, with values of $67.47 \mathrm{mmHg}, 70.16 \mathrm{mmHg}$, and $72.55 \mathrm{mmHg}$ in the normal-weight, overweight, and obese groups, respectively $(\mathrm{F}=7.17, p=.001)$. Waist circumference also showed significant differences among the groups, with val- 
ues of $68.72 \mathrm{~cm}, 83.12 \mathrm{~cm}$, and $89.64 \mathrm{~cm}$ in the normal weight, overweight, and obese groups, respectively $(\mathrm{F}=177.76, p<.001)$. Triglyceride levels varied significantly among the groups, with values of $81.39 \mathrm{mg} / \mathrm{dL}, 96.92 \mathrm{mg} / \mathrm{dL}$, and $108.62 \mathrm{mg} / \mathrm{dL}$ in the normal-weight, overweight, and obese groups, respectively $(\mathrm{F}=6.57, p=.002)$. Fasting blood sugar also varied among the groups, with levels of $90.84 \mathrm{mg} / \mathrm{dL}, 92.94 \mathrm{mg} / \mathrm{dL}$, and 94.81 $\mathrm{mg} / \mathrm{dL}$ in the normal-weight, overweight, and obese groups, respectively $(\mathrm{F}=3.15, p=.047)$. Lastly, ALT also showed significant differences among the groups, with levels of $13.17 \mathrm{IU} / \mathrm{L}$, 19.31 IU/L and 31.62 IU/L in the normal-weight, overweight, and obese groups, respectively $(\mathrm{F}=12.03, p<.001)$.

\section{Factors Influencing Obesity in Adolescents}

To analyze the sociodemographic characteristics and lifestyle factors related to obesity in adolescents, multinomial logistic regression was conducted, including all variables that showed a significance level of $\leq .20$ in the simple logistic regression [22]. Since distorted perceptions of body shape were defined on the basis of self-rated body shape, meaning that those 2 variables were highly correlated, distorted percep- tions of body shape were input alone. In a multinomial logistic regression analysis including distorted perceptions of body shape and carbohydrate intake, distorted perceptions of body shape were found to be a factor influencing overweight $(\mathrm{OR}=0.15, p<.001)$, while carbohydrate intake was found to influence obesity $(\mathrm{OR}=0.97, p=.028)$ (Table 4). In other words, adolescents who perceived their weight in a distorted way were 0.15 times less likely to be overweight than adolescents who did not (95\% CI, 0.07 0.34) and as carbohydrate intake increased by every $10 \mathrm{~g}$, obesity was found to decrease by 0.97 times (95\% CI, 0.94 0.99).

\section{DISCUSSION}

The present study examined associations of obesity among Korean adolescents with sociodemographic characteristics, lifestyle factors, and health parameters, and to analyze the factors that influenced obesity in adolescents using the raw data from the first year of the seventh KNHANES. Overall, 9.7\% and $11.9 \%$ of the subjects were found to be obese and overweight, respectively. This shows that 1 out of 5 Korean adolescents is overweight or above and 1 out of 10 Korean adoles-

Table 3. Health Parameters of Adolescents according to Obesity

\begin{tabular}{|c|c|c|c|c|c|c|}
\hline \multirow[t]{2}{*}{ Characteristics } & $\begin{array}{l}\text { Normal } \\
(n=336)\end{array}$ & $\begin{array}{l}\text { Overweight } \\
\qquad(\mathrm{n}=54)\end{array}$ & $\begin{array}{l}\text { Obesity } \\
(n=46)\end{array}$ & $\begin{array}{c}\text { Total } \\
(N=436)\end{array}$ & \multirow[t]{2}{*}{$\mathrm{F}$} & \multirow{2}{*}{$p$} \\
\hline & $\mathrm{n}(\%)^{*}$ or $\mathrm{M} \pm \mathrm{SD}$ & $\mathrm{n}(\%)^{*}$ or $\mathrm{M} \pm \mathrm{SD}$ & $\mathrm{n}(\%)^{*}$ or $\mathrm{M} \pm \mathrm{SD}$ & $\mathrm{n}(\%)^{*}$ or $\mathrm{M} \pm \mathrm{SD}$ & & \\
\hline SBP (mmHg) & $108.14 \pm 0.62$ & $113.19 \pm 1.44$ & $120.40 \pm 1.81$ & $110.11 \pm 0.61$ & 24.15 & $<.001$ \\
\hline $\mathrm{DBP}(\mathrm{mmHg})$ & $67.47 \pm 0.47$ & $70.16 \pm 0.86$ & $72.55 \pm 1.64$ & $68.37 \pm 0.43$ & 7.17 & .001 \\
\hline $\mathrm{WC}(\mathrm{cm})$ & $68.72 \pm 0.37$ & $83.12 \pm 0.97$ & $89.64 \pm 1.31$ & $72.86 \pm 0.48$ & 177.76 & $<.001$ \\
\hline $\mathrm{TC}(\mathrm{mg} / \mathrm{dL})$ & $161.92 \pm 1.77$ & $167.84 \pm 4.33$ & $166.51 \pm 4.56$ & $163.19 \pm 1.54$ & 1.06 & .351 \\
\hline $\mathrm{TG}(\mathrm{mg} / \mathrm{dL})$ & $81.39 \pm 2.88$ & $96.92 \pm 8.06$ & $108.62 \pm 7.91$ & $86.38 \pm 2.89$ & 6.57 & .002 \\
\hline FBS (mg/dL) & $90.84 \pm 0.40$ & $92.94 \pm 1.14$ & $94.81 \pm 2.07$ & $91.55 \pm 0.36$ & 3.15 & .047 \\
\hline HbA1c (\%) & $5.33 \pm 0.02$ & $5.36 \pm 0.05$ & $5.45 \pm 0.06$ & $5.35 \pm 0.02$ & 2.31 & .104 \\
\hline AST (IU/L) & $17.88 \pm 0.38$ & $18.61 \pm 0.73$ & $22.90 \pm 2.07$ & $18.52 \pm 0.42$ & 3.00 & .054 \\
\hline ALT (IU/L) & $13.17 \pm 0.81$ & $19.31 \pm 1.74$ & $31.62 \pm 4.85$ & $15.98 \pm 0.98$ & 12.03 & $<.001$ \\
\hline
\end{tabular}

*Weighted \%; SBP=Systolic blood pressure; DBP=Diastolic blood pressure; WC=Waist circumference; TC=Total cholesterol; TG=Triglyceride; FBS=Fasting blood sugar; AST=Aspartate aminotransferase; ALT=Alanine aminotransferase.

Table 4. Factors Influencing Overweight and Obesity in Adolescents

$(N=436)$

\begin{tabular}{|c|c|c|c|c|c|c|c|c|}
\hline \multirow{2}{*}{ Variables } & & \multirow{2}{*}{ Categories } & \multicolumn{3}{|c|}{ Overweight } & \multicolumn{3}{|c|}{ Obesity } \\
\hline & & & OR & $95 \% \mathrm{CI}$ & $p$ & OR & $95 \% \mathrm{CI}$ & $p$ \\
\hline \multirow[t]{2}{*}{ Demographic } & Distorted perception & No & 1.00 & & & 1.00 & & \\
\hline & about body shape & Yes & 0.15 & $0.07 \sim 0.34$ & $<.001$ & 1.73 & $0.88 \sim 3.40$ & .166 \\
\hline Lifestyle & Carbohydrates (10 g/day) & & 1.01 & $0.99 \sim 1.04$ & .271 & 0.97 & $0.94 \sim 0.99$ & .028 \\
\hline
\end{tabular}

$\mathrm{OR}=$ Odds ratio; $\mathrm{CI}=$ Confidence interval. 
cents is obese.

Unlike the results of previous studies [8,9], in which the prevalence of obesity varied according to sex, age, and families' socioeconomic level, no significant differences were found in this study in age, sex, place of residence, or household income among the normal-weight, overweight, and obese groups. In the overweight group, $62.1 \%$ and $37.9 \%$ of the participants were male and female, respectively, while the sex distribution was more similar in the obese group, with proportions of $52.4 \%$ and $47.6 \%$ for male and female participants, respectively. However, a statistically significant association between obesity and sex was not found. The discrepancy between our results and those of previous research that used national-level data likely due to differences over time between 2013 and 2016, as well as differences in the subjects themselves and obesity classification standards. The study of Lee and Yi [9] was conducted on middle school students, and the study of Im et al. [8] classified adolescents with a $\geq$ BMI 25 $\mathrm{kg} / \mathrm{m}^{2}$ as obese.

In this study, self-rated body shape and distorted perceptions of body shape showed significant variation among the normal-weight, overweight, and obese groups, and $43.0 \%$ of all subjects had distorted perceptions of their body shape. This rate is more than twice as high than the rate reported in a previous study [4] that analyzed data from the 2005 KNHA NES and found that $18.4 \%$ of adolescents had distorted perceptions of their body shape; this discrepancy shows that it has become significantly more common over the last 10 years for adolescents to have distorted perceptions of their body shape. Adolescents' distorted perceptions of their body shape may become more common due to the tendency in the adolescent period for an increasing interest in one's body and appearance and desire for social recognition; as such, adolescents may be obsessed with themselves or look at themselves with a critical eye [23]. A social atmosphere that places paramount importance on appearance and the influence of the mass media, which promote a slim body as the standard of beauty, hinder adolescents' healthy perceptions of their body shape. In particular, in this study, $15.9 \%$ and $0.3 \%$ of normal-weight participants perceived themselves as slightly fat and very fat, respectively, and $9.5 \%$ of the overweight group perceived themselves as very fat. In a previous study [4], female students who perceived themselves as fat, but were not actually obese, were 4.98 times more likely to experience depression than other female students without such perceptions, showing that perceptions of body shape were associated with mental health. Therefore, adolescents' perceptions of their body shape should be investigated, and they should receive help to perceive themselves correctly, without distortions in their body image.
No significant differences in nutrient intake or physical activity were found among the normal-weight, overweight, and obese groups. Daily high-intensity exercise or leisure activity time was 56.10 minutes, 61.01 minutes, and 48.86 minutes in the normal-weight, overweight, and obese groups, respectively. Daily mid-intensity exercise or leisure activity time was 46.29 minutes, 50.11 minutes, and 40.80 minutes in the normalweight, overweight, and obese groups, respectively, which was not a significant difference. However, the standard deviation of nutrient intake and physical activity in the obese group was large, indicating that there were large differences within that group. Adolescents' daily necessary and recommended protein intake amounts according to the Dietary Reference Intakes for Koreans are 40 50 g and 50 65 g [24], respectively, and the protein intake amount of all groups was about $80 \mathrm{~g}$, or double the necessary intake amount. Protein intake is recommended [23] for adolescents in the stage of growth, and sufficient intake is encouraged for growth. However, placing a heavy emphasis on this guideline can lead to excessive intake. In a previous study on children and adolescents [12], protein intake in both the normal-weight and obese groups was higher than the recommended amount, similarly to this study, while fiber intake was lower than recommended. Therefore, more precise education and instruction should be provided to promote healthy nutrient intake among adolescents.

There were no significant differences in sitting and lying time or sleeping hours among the normal-weight, overweight, and obese groups. As the daily life of adolescents is similar, without meaningful individual differences in an education system that focuses only on college entrance exams, it is unsurprising that their activity and sleep patterns were similar. Furthermore, the difference between sleeping hours on weekdays and weekends among all 3 groups was on average 1.5 hours, which shows that participants tended to have a different sleep pattern on weekends, when school is not in session, in comparison to that on weekdays. Short sleeping time increases the likelihood of obesity [14]. However, irregular sleeping patterns, in which the specific times of going to bed and waking vary and/or sleeping time changes, such as from short to long or from long to short, are also associated with obesity [20]. In other words, irregular sleep patterns in schoolage children and adolescents and excessive sleep on weekends have been reported to be associated with the excessive accumulation of fat cells [20]. Therefore, changes in sleep patterns should be measured, rather than simple sleeping time, and further research should investigate possible correlations between obesity in adolescents and changes in their sleeping schedule through the observation of sleep patterns for a certain period of time or by having research subjects make a sleep daily $\log$. 
In this study, efforts to control weight were significantly different among the normal-weight, overweight, and obese groups. In particular, $71.2 \%$ of overweight participants made efforts to lose weight, while only $45.4 \%$ of obese participants did so. In other words, despite the desperate need for efforts to control weight in obese adolescents, they made fewer efforts to do so than overweight adolescents. Adolescent obesity is highly likely to develop into adult obesity or severe obesity [25]. For this reason, measures should be prepared to motivate obese adolescents to keep making efforts to lose weight. Developing and executing an effective weight loss program to prevent obesity may also be effective, since many overweight adolescents reported making efforts to lose weight. Furthermore, $28.3 \%$ of the normal-weight group stated that they had tried to lose weight, which is associated with the result that $16.2 \%$ of the normal-weight group perceived themselves as fat. Distorted perceptions of body shape can lead to undesirable efforts to lose weight, such as inappropriate meals or exercise, which can have a negative effect on health. Therefore, adolescents should be educated and guided to have positive perceptions of their bodies in order to prevent them from making ill-advised efforts to lose weight.

To investigate whether obesity in adolescents was associated with health parameters, bodily measures and blood test measures were analyzed. Systolic blood pressure, diastolic blood pressure, waist circumference, and triglyceride, fasting blood sugar, and ALT levels were found to be higher in the overweight and obese groups. Metabolic syndrome, which combines hypertension, dyslipidemia, and hyperglycemia, is reported to be associated with obesity [5], and a previous study [21] conducted on children and adolescents who participated in a nutrition camp reported that $36.4 \%$ of obese adolescents met the diagnostic criteria for metabolic syndrome ( 3 or more of the following items: waist circumference at or above the 90th percentile, triglycerides $\geq 150 \mathrm{mg} / \mathrm{dL}$, high-density lipoprotein cholesterol $<40 \mathrm{mg} / \mathrm{dL}$, systolic blood pressure $\geq$ $130 \mathrm{mmHg}$, diastolic blood pressure $\geq 85 \mathrm{mmHg}$, and fasting blood sugar $\geq 100 \mathrm{mg} / \mathrm{dL}$ ) and $59.1 \%$ of them met at least 1 of the diagnostic criteria. This study, which used a national-level sample, yielded results that agreed with the previous study. In particular, it is notable that bodily measures and blood test measures were high in both overweight and obese adolescents. Therefore, it is recommended to examine the blood lipid levels of overweight adolescents, as well as obese adolescents, and to manage any associated health problems promptly [6]. A previous study [21] emphasized that intensive management is needed for overweight and obese adolescents before metabolic syndrome and cardiovascular disease develop because their insulin resistance is higher than that of normal adolescents, even if they do not have metabolic syndrome.
The multinomial logistic regression analysis to investigate the sociodemographic characteristics and lifestyle factors that were associated with obesity in adolescents showed that distorted perceptions of body shape and carbohydrate intake influenced overweight and obesity, respectively. The risk of overweight among adolescents who had distorted perceptions of their body shape was 0.15 times lower than that of adolescents who did not have such perceptions. While many adolescents in this study perceived themselves as being no more overweight or obese than they actually were, some of the normal-weight and overweight adolescents thought they were fatter than they actually were and made efforts to lose weight. It is thought that this result partially influenced the association between distorted perceptions of body shape and the reduced risk of overweight. However, since $43.0 \%$ of the subjects of this study had distorted perceptions of their body shape, and a previous study [4] reported that distorted perceptions of body shape were associated with depression, it would seem that there is a need to carefully consider the management of mental health among adolescents who have distorted perceptions of their body shape.

In this study, the OR of obesity per $10 \mathrm{~g}$ increase in adolescents' carbohydrate intake was 0.97 , indicating that the intake of carbohydrates was unexpectedly associated with the reduction of obesity. An explanation for this can be inferred from the difference in the intake ratio of various nutrients between the obese group and the normal-weight group. The caloric intake of the obese group was the lowest among the 3 groups. However, although this trend was not statistically significant, the obese group combined a high fat intake with a low carbohydrate intake, and they showed the highest fat-tocaloric intake ratio. This can be interpreted as indicating that obese participants were regulating their diet by reducing carbohydrate intake, not fat intake. Therefore, the results of this study suggest that analyzing adolescents' dietary patterns, with the goal of improving them, is a high priority for weight control among adolescents. The findings of a previous study [21], which was conducted on children and adolescents and showed that there was a difference in fatty acid intake between the normal-weight group and obese group, support this inference. In this study, the nutrient intake of adolescents was investigated quantitatively in terms of the amount of calorie, protein, fat, and carbohydrate intake. However, qualitative aspects, such as intake of minerals or food additives, can also be associated with obesity [12], so the impact of these factors on obesity should also be analyzed.

As this study had a cross-sectional design, there are limitations in interpreting causal relationships between obesity and lifestyle factors, such as nutrient intake, physical activity, and sleep, and distorted perceptions of body shape. More- 
over, as the analysis was conducted using the raw data of the KNHANES, several variables related to obesity in adolescents could not be investigated. However, this study is meaningful in that common characteristics associated with obesity among Korean adolescents were identified from data collected from subjects who were selected from the whole nation through a probability sampling method.

\section{CONCLUSION}

This study analyzed the raw data from the first year of the seventh Korea National Health and Nutrition KNHANES to investigate the associations of obesity among Korean adolescents with sociodemographic characteristics, lifestyle factors, and health parameters, and to analyze the factors that influenced obesity in adolescents. The study results revealed that $9.7 \%$ of the subjects were obese, and $11.9 \%$ were overweight. No significant differences were found among the normalweight, overweight, and obese groups according to sociodemographic characteristics, such as age, sex, place of residence, and household income, and lifestyle patterns, such as nutrient intake, physical activity, and sleep. However, systolic blood pressure, diastolic blood pressure, waist circumference, and triglyceride, fasting blood sugar, and ALT levels of overweight and obese adolescents were higher than those of normal-weight adolescents, and distorted perceptions of body shape and carbohydrate intake were factors that influenced overweight and obesity, respectively. Therefore, weight control programs including improvements of dietary habits are needed for obese or overweight adolescents before the onset of health problems, such as metabolic syndrome and cardiovascular disease. Moreover, although distorted perceptions of body shape were found to lower the risk of overweight, such perceptions are associated with depression in adolescents. Therefore, schools and families should make efforts to help adolescents establish positive perceptions of their body shape.

\section{Conflict of interest}

No existing or potential conflict of interest relevant to this article was reported.

\section{REFERENCES}

1. Park YS, Lee DH, Choi JM, Kang YJ, Kim CH. Trend of obesity in school age children in Seoul over the past 23 years. Korean Journal of Pediatrics. 2004;47(3):247-257.

2. Korean Ministry of Education. A sample survey from school health examination [Internet]. Sejong: Korean Ministry of Education; 2015 [cited 2018 July 27]. Available form:
http://www.moe.go.kr/boardCnts/view.do?boardID=339\&lev= $0 \&$ status $Y \mathrm{~N}=\mathrm{C} \& \mathrm{~s}=$ moe\&m $=02 \&$ opType $=\mathrm{N} \&$ boardSeq $=58466$.

3. Bae H, Ryou B. The effects of obesity on school adjustment and academic achievement among middLe school students. Studies on Korean Youth. 2015;26(1):79-109. https://doi.org/10.14816/sky.2015.26.1.79

4. Hwang IC, Lee KS, Park DK, Jung EY, Choi CH, Cho SJ, et al. Association with self-perception for obesity and mental health among Korean adolescent. Korean Journal of Child and Adolescent Psychiatry. 2011;22(2):112-119.

5. Kim SH, Park MJ. Management of childhood obesity. Journal of the Korean Medical Association. 2017;60(3):233-241. https://doi.org/10.5124/jkma.2017.60.3.233

6. Kumar S, Kelly AS. Review of childhood obesity: From epidemiology, etiology, and comorbidities to clinical assessment and treatment. Mayo Clinic Proceedings. 2017;92(2):251-265. https://doi.org/10.1016/j.mayocp.2016.09.017

7. Park HA, Cho J. Economic activities and socioeconomic status of morbidLy obese Korean adults. Journal of Obesity and Metabolic Syndrome. 2011;20(4):210-218.

8. Im Y, Oh WO, Suk MH. Adolescent health behaviors according to body mass index. Child Health Nursing Research. 2017;23(1):1-9. https://doi.org/10.4094/chnr.2017.23.1.1

9. Lee J, Yi K. An analysis of the determinants of adolescents' health inequality in Korea: A view from the students' self-rated health condition and obesity. The Korean Educational Review. 2015;21 (2):221-247.

10. Hwang I, Bang KS. Factors affecting obesity and overweight in Korean preschool children: Based on the Korea national health and nutrition examination survey 2013-2014. Child Health Nursing Research. 2016;22(4):237-246. https://doi.org/10.4094/chnr.2016.22.4.237

11. Alsharairi NA, Somerset SM. Skipping breakfast in early childhood and its associations with maternal and child BMI: A study of 2-5-year-old Australian children. European Journal of Clinical Nutrition. 2016;70(4):450-455. https://doi.org/10.1038/ejcn.2015.184

12. Yang SW, Lee HS, Kim JE, Kim YM, Seo YG, Park KH, et al. Assessment of diet quality by weight status and its association with obesity in children and adolescents. Journal of the Korean Dietetic Association. 2017;23(3):263-273. https://doi.org/10.14373/JKDA.2017.23.3.263

13. Peterson NE, Sirard JR, Kulbok PA, DeBoer MD, Erickson JM. Sedentary behavior and physical activity of young adult university students. Research in Nursing and Health. 2018;41(1):30-38. https://doi.org/10.1002/nur.21845

14. Morgan D, Tsai SC. Sleep and the endocrine system. Critical Care Clinics. 2015;31(3):403-418. https://doi.org/10.1016/j.ccc.2015.03.004

15. World Health Organization. Global health risks: Mortality and 
burden of disease attributable to selected major risks. 1st ed. Geneva, CH: Author; 2009. p. 1-62.

16. Chu J, Kwon E, Nah EH. The relationship between abnormal liver function and metabolic risk factors in obese children and adolescents. Korean Journal of Health Education and Promotion. 2017;34 (3):59-70. https:// doi.org/10.14367/kjhep.2017.34.3.59

17. Lee H, Park, ES, Yu JK, Yun EK. Non-linear system dynamics simulation modeling of adolescent obesity: Using Korea youth risk behavior web-based survey. Journal of Korean Academy of Nursing. 2015;45(5):723-732

18. Korea Centers for Disease Control and Prevention. The seventh Korea national health and nutrition examination survey (KNHA NES VII-1). Survey Report. Seoul: Korea Centers for Disease Control and Prevention; 2018 January. Report No.: 117002.

19. Kim JH, Yun S, Hwang SS, Shim JO, Chae HW, Lee YJ, et al. The 2017 Korean national growth charts for children and adolescents: Development, improvement, and prospects. 2018;61(5):135-149. https://doi.org/10.3345/kjp.2018.61.5.135

20. Miller AL, Lumeng JC, LeBourgeois MK. Sleep patterns and obe- sity in childhood. Current Opinion in Endocrinology, Diabetes, and Obesity. 2015;22(1):41-47.

https://doi.org/10.1097/MED.0000000000000125

21. Kim JH, Kim EK. The relationship among insulin resistance, blood profiles and nutrient intake in overweight or obese children and adolescents. Korean Journal of Community Nutrition. 2012;17(5): 530-542. https://doi.org/10.5720/kjcn.2012.17.5.530

22. Menard S. Applied logistic regression analysis. 2nd ed. Thousand Oaks, CA: Sage; 1995. p. 54-57.

23. Leifer G, Fleck E. Growth and development across the lifespan: A health promotion focus. 2nd ed. St. Louis, MO: Elsevier; 2012. p. 183-194.

24. Ministry of Health and Welfare, and The Korean Nutrition Society. Korean dietary reference intakes for 2015. 1st ed. Sejong: Ministry of Health and Welfare; 2015. p. 131-135.

25. The NS, Suchindran C, North KE, Popkin BM, Gordon-Larsen P. Association of adolescent obesity with risk of severe obesity in adulthood. Journal of the American Medical Association. 2010;304 (18):2042-2047. https://doi.org/10.1001/jama.2010.1635 